\title{
Experimental studies on hydrogen hydrate with tetrahydrofuran by differential scanning calorimeter and in-situ Raman
}

Cai, Jing; Tao, Yuan-Qing; von Solms, Nicolas; Xu, Chun-Gang; Chen, Zhao-Yang; Li, Xiao-Sen

Published in:

Applied Energy

Link to article, DOI:

10.1016/j.apenergy.2019.03.179

Publication date:

2019

Document Version

Peer reviewed version

Link back to DTU Orbit

Citation (APA):

Cai, J., Tao, Y-Q., von Solms, N., Xu, C-G., Chen, Z-Y., \& Li, X-S. (2019). Experimental studies on hydrogen hydrate with tetrahydrofuran by differential scanning calorimeter and in-situ Raman. Applied Energy, 243, 1-9. https://doi.org/10.1016/j.apenergy.2019.03.179

\section{General rights}

Copyright and moral rights for the publications made accessible in the public portal are retained by the authors and/or other copyright owners and it is a condition of accessing publications that users recognise and abide by the legal requirements associated with these rights.

- Users may download and print one copy of any publication from the public portal for the purpose of private study or research.

- You may not further distribute the material or use it for any profit-making activity or commercial gain

- You may freely distribute the URL identifying the publication in the public portal 


\section{Experimental Studies on Hydrogen Hydrate in the}

\section{presence of Tetrahydrofuran by Differential}

\section{Scanning Calorimeter and in-situ Raman*}

Jing Cai ${ }^{a, b, c, d, e, f}$, Yuan-Qing Taoo ${ }^{a, b, c, d, e}$, Nicolas von Solms ${ }^{f}$, Chun-Gang Xu ${ }^{\text {a,b,c,d }}$, Zhao-Yang Chen ${ }^{a, b, c, d}$, Xiao-Sen Lij ${ }^{a, b, c, d,+}$

${ }^{a}$ Guangzhou Institute of Energy Conversion, Chinese Academy of Sciences, Guangzhou, 510640, China

${ }^{b}$ CAS Key Laboratory of Gas Hydrate, Guangzhou, 510640, China

'Guangdong Provincial Key Laboratory of New and Renewable Energy Research and Development, Guangzhou, 510640, China

${ }^{d}$ Guangzhou Center of Gas Hydrate Research, Chinese Academy of Science, Guangzhou, 610640, China

eUniversity of Chinese Academy of Sciences, Beijing, 100049, China

${ }^{f}$ Center for Energy Resources Engineering, Department of Chemical and Biochemical Engineering, Technical University of Denmark, Lyngby, 2800 Kgs., Denmark

\section{Abstract}

Clathrate hydrates are have potential as environment-friendly materials for storing hydrogen. under the right conditions of temperature and pressure. In this work, tetrahydrofuran (THF) aqueous solution with concentration of 3.0 mol\% was adopted to investigate hydrogen storage process. Moreover, thermal properties of hydrate was measured by high pressure differential scanning calorimeter ( $h p$-DSC), and mechanism of hydrate-based hydrogen storage was studied by in-situ Raman. Especially, gas uptake, morphology and structures change of compounds from gas/liquid

\footnotetext{
* The short version of the paper was presented at ICAE2018, Aug 22-25, Hong Kong. This paper is a substantial extension of the short version of the conference paper.

${ }^{+}$Corresponding author. Tel: +86-20-87057037; fax: +86-20-87034664. E-mail address: lixs@ms.giec.ac.cn (X.-S. Li)
} 
interface towards hydrate layer were monitored in the process of hydrate formation. Thermal experiments illustrate that thermal data for THF-hydrogen binary hydrate under extra high pressures could be effectively obtained by $h p$-DSC, moreover, memory effect shows no influence on thermal state of hydrate but affects water aggregation weakly. Kinetics experiments and microscopic analysis illustrate that a special pressure drop and some THF hydrates with unstable structure can be found under conditions of $273.15 \mathrm{~K}$ and $14.53 \mathrm{MPa}$. The pressure drop involves into hydrogen molecules tunneling movements among hydrate cavities. Moreover, hydrogen molecules show a positive effect on the stability of binary hydrate. Further, the density of $1.875 \mathrm{~g} /$ liter water shows that hydrogen storage process via clathrate hydrate is an excellent method to store hydrogen.

Keywords: Hydrate, hydrogen storage, THF, mechanism

\section{Introduction}

Gas hydrate is a kind of crystalline compound formed by host framework of water molecules via hydrogen bonds and guest molecules encaged into cavities through van der Waals under appropriate conditions of low temperature and/or high pressure.[1] Generally, the host water framework is built with three different cavities, including 12 -hedra $\left(5^{12}\right)$, 14hedra $\left(5^{12} 6^{2}\right)$ and 16 -hedra $\left(5^{12} 6^{4}\right)$. The guest molecules, including different hydrate promoter molecules and various gas molecules, are encapsulated into these cavities via van der Waal force. In terms of size and characteristic of guest molecule, cubic structure (sl), cubic structure II (sII) and hexagonal structure $\mathrm{H}(\mathrm{sH})$ can be found.[2] Due to these encaging advantages, natural gas hydrate (NHG) is widely considered as the promising alternative energy resource in the future. Besides, it is also widely investigated as a special material to store and transit hydrogen, natural gas and carbon dioxide.[3]

With the depletion of fossil fuels, various sustainable energy sources have attracted the eyes of researchers. Especially, hydrogen with advantages of being clean, environmental-friendly and efficient fuel, is an active research area worldwide. Although liquid hydrogen, compressed hydrogen gas, molecular hydrogen adsorption on solids, and bonding in hydrocarbons or metal hydrides have been developed to store hydrogen under their available conditions, the investigations on developing more efficient materials and methods for hydrogen storage are still being performed intensively.[4-7] The new materials are expected for the large-scale application without environmental hazards effect, and further can be recycled after the process. Consequently, clathrate hydrate presents an excellent advantage on hydrogen storage. Since 1990s, different structures of hydrogen hydrate have been reported, including clathrate 1 structure with space group of $R \overline{3}$, and clathrate 2 structure with space group of $F d \overline{3} m$.[8] Mao et al.[9] also proved that molecular hydrogen storage is an attractive alternative method for storing and transiting hydrogen. By this method, hydrogen molecules can be encaged into hydrate cavities constituted by water molecules. Moreover, the hydrate containing hydrogen could keep stable under certain condition for a long time due to self-protect effect of hydrate itself. [10] This type of hydrogen storage in forms of clathrate hydrate belongs to one of hydrate-based technologies. Expect for storing hydrogen, hydrate-based technologies can also be widely adopted to purify hydrogen from fuel gas together with pre-combustion capture of carbon dioxide, [11-15] and recover hydrogen from hydrogenation plant off-gas etc.[16] 
For the formation of the hydrate containing hydrogen, John et al.[17] formed hydrogen hydrate using a high-pressure separator with SRC-II process (Solvent Refined Coal II Process) and found that hydrogen hydrate failed to be stable according to its Kihara parameters. However, Vos et al.[18] fisttly formed hydrogen hydrate in the pressure range of $0.75 \mathrm{GPa}$ to $3.1 \mathrm{GPa}$. In order to understand occupancy of hydrogen molecules into hydrate cavities, Mao et al.[19] adopted Raman spectrometry and x-ray diffraction (XRD) and found that hydrogen molecules were encaged into the cavities with hydrogen ploy-molecule clusters, forming sll hydrate. Lu et al.[20] also proved that hydrogen molecules were trapped into the cavities in forms of clusters and different molecule clusters occupied into different small and medium cavities. Although structures and mechanism of hydrogen hydrate formation were deeply under harsh conditions of ultra-high pressure and ultra-low temperature, such conditions are unavailable for large-scale industrialization. Thus, thermodynamic hydrate promoter, such as tetrahydrofuran (THF), tetrabutylammonium bromide (TBAB) and cyclopentane (CP), etc., is adopted to moderate pressure or enhance temperature of hydrogen hydrate formation. Hester et al.[21] investigated THF-hydrogen binary hydrate using high resolution neutron diffraction, and found that molecular hydrogen occupancy was affected by pressures with addition of THF as promoter. According to the report of Florusse et al.,[22] pressure could be reduced to $5 \mathrm{MPa}$ from ultra-high pressure at $280 \mathrm{~K}$ by adding THF. In addition, Strobel et al.[23] reported that hydrogen could form sH hydrates with cyclohexanone as promoter. Qin et al.[24] ever adopted a new mixed hydrate-the oxygen-hydrogen hydrate to store hydrogen. Veluswamy et al.[25] investigated macroscopic kinetics of hydrogen hydrate formed in systems with THF, TBAB and CP, and found that highest hydrogen density for sll hydrate with 0.0173 mole of gas/mole of water could be obtained in 3.5 mol\% THF solution under conditions of $12 \mathrm{MPa}$ and $279.2 \mathrm{~K}$, showing a better hydrogen storage capacity in comparison with semi-clathrate hydrate containing TBAB. Veluswamy et al.[26] also adopted propane to form another sll hydrate containing hydrogen, and proposed a two-step hydrate crystal growth mechanism based on kinetic experimental results.[27] Besides, hydrogen storage capacity of other hydrates with addition of tetrahydrothiophene, furan, tetrabutylammonium fluoride, and so on, were performed as well.[28-36] However, THF still shows much better effect on both hydrogen storage capacity and hydrate formation rate. Therefore, THF was adopted as hydrate promoter in this work.

To clear formation mechanism of hydrate containing hydrogen, some calculations and experiments were ever carried out from the microscopic point of view. Zhao et al.[37] reported that guest molecules with various size and hydrophilicity presented different characteristics when they were participating in the process of hydrate formation in microscopic media. Moreover, Raman shift changed involving into guest-host hydrogen bonding, according to the results reported by Lim et al.[38] in the system with diazine isomers. Park et al.[39] proposed that small nitrogen molecules influenced cage occupancy of hydrogen molecules. However, most of experiments were achieved in ice system instead of liquid system. However, it is important to understand hydrate formation mechanism in liquid system. Thus, the process of hydrate nucleation and crystal growth in or around gas/liquid interface was investigated in this system with THF. To obtain comprehensive information of THF-hydrogen binary hydrate, two groups of experiments were achieved, involving into thermodynamics, macroscopic kinetics and microscopic analysis. In particular, thermodynamic experiments were carried out using high pressure differential scanning calorimeter (hp-DSC) to understand phase 
behavior during hydrate formation and dissociation, performing thermos-gram and thermal parameters of THFhydrogen hydrate. Kinetic data and morphology were recorded in the process of THF-hydrogen binary hydrate formation, meanwhile, structure changes of compounds in and around the gas/liquid interface were measured using in-situ Raman spectrometer.

\section{Experimental section}

In this work, two different groups of experiments were carried out in THF solution with concentration of 3.0 mol\% to clear mechanism of hydrate-hydrogen formation. Materials and equipment were detailed in Supporting Information. Thermodynamic experiments were performed by using the $h p$-DSC, as shown in Fig. S1, to understand the phase behaviors of hydrate formation and dissociation, and further obtain thermos-gram and thermal parameters of THFhydrogen hydrate. Macroscopic experiments were carried out with the equipment shown in Fig. S2. Kinetic data and morphologies were recorded in the process of THF-hydrogen binary hydrate formation. In-situ Raman spectrometer experiments were carried out in the same equipment adopted for macroscopic experiments to determine structure change of compounds in and around gas/liquid interface in the process of hydrate formation.

For thermodynamic experiments, after desired mass of water and THF solution was added into a sample cell, the hydrogen was injected into by a pressure panel, then the thermal cycling performed following the program, as shown in Fig. S1 and Fig. S3. For macroscopic experiments, $80 \mathrm{~mL}$ solution containing water and water-soluble promoter of THF was added into the crystallizer without stirring, as shown in Fig. S3. Then, the jacket temperature was set at the temperature of $273.15 \mathrm{~K}$. When the temperature was constant, gas was introduced into crystallizer and pressurized up to $14.53 \mathrm{MPa}$. In the process of hydrate formation, pressures and temperatures were recorded, and morphology of hydrate nucleation or crystallization in and around the gas/liquid interface was filmed by a Nikon digital camera. Meanwhile, in-situ Raman spectrometer measurements were carried out in the same process. For in-situ Raman experiment, Raman spectrometer (Horiba, LabRAM HR) with a single Monochromator of 600 grooves/mm grating and a multichannel air-cooled CCD (charge coupled device) detector was employed to characterize the structure changes of the compounds in and around the gas/liquid interface before and during the hydrate formation. A $532 \mathrm{~nm}$ incident laser beam was used. The Ar-ion laser was focused on the sample by a $1 \times$ microscope objective. The spectroscopic data were detected by a CCD detector with an energy resolution of $100 \mathrm{~mW}$ and recorded with a $10 \mathrm{~s}$ integration time over 5-30 scans. The silicon (Si) crystal standard of $520.7 \mathrm{~cm}^{-1}$ was adopted to calibrate the subtractive spectrograph. After adding THF solution into the crystallizer, compounds in and around gas/liquid interface were initial measured by using in-situ Raman spectrometer to obtain the characteristics of gas/liquid interface without effect of hydrogen molecules. Next, when hydrogen was injected into the crystallizer to the desired value of $14.53 \mathrm{MPa}$, compounds in and around gas/liquid interface were measured again before hydrate formation. Moreover, this measurement was recorded as Raman spectra at $0 \mathrm{~h}$. In the process of hydrate formation, compounds in and around gas/liquid interface were measured at $48 \mathrm{~h}, 96 \mathrm{~h}$, $132 \mathrm{~h}$, and $168 \mathrm{~h}$, respectively. 


\section{Results and discussion}

\subsection{Thermal properties of THF-hydrogen binary hydrate}

In order to investigate the formation and dissociation behavior of the THF-hydrogen binary hydrate, a $h p$-DSC was adopted to perform thermodynamic experiments in fresh and memory THF solution. The mass of THF solution with 894 mg was injected into $h p$-DSC sample cell to form THF-hydrogen binary hydrate. All thermodynamic experiments were carried out using $h p$-DSC in the same memory THF solution with concentration of 3.0 mol\% under pressures of 18.00 $\mathrm{MPa}, 25.00 \mathrm{MPa}$ and $34.00 \mathrm{MPa}$, respectively.

\subsubsection{Memory effect}

Fig. 1 shows thermograms of THF-hydrogen binary hydrate at the pressure of $18.00 \mathrm{MPa}$ in fresh and memory THF solution. The formation and dissociation behavior of THF-hydrogen binary hydrate formed in fresh and memory THF solution are quite similar. For each temperature decreasing process, two major exothermic peaks, corresponding to hydrate formation and ice freezing, can be observed. The first exothermic peak is assigned to hydrate formation, it occurs at $265.19 \mathrm{~K}$ in the fresh solution and $263.82 \mathrm{~K}$ in the memory solution. Both of these temperature are lower than that of $273.15 \mathrm{~K}$ obtained in pure water system,[40] because freezing point of water can be reduced significantly by adding soluble organic compound of THF.[41] The temperature relative to hydrate formation in the memory solution is 1.27 K lower than that obtained in the fresh solution. It involves into the existence of residual relic water framework in the memory solution. Moreover, such heat relative to framework construction from the relic water framework towards hydrate cavities is too weak to be detected. In addition, tiny exothermic peaks appearing at around $261.91 \mathrm{~K}$ before ice freezing, could be resulted from the heat releasing, relative to water molecules in this kind of residual relic framework freezing towards ice. The exothermic peak is assigned to ice freezing, it shows at $260.33 \mathrm{~K}$ and $260.89 \mathrm{~K}$ in the fresh solution and in the memory solution, respectively. Especially, the ice freezing temperature obtained in the memory solution is $0.56 \mathrm{~K}$ higher than that obtained in the fresh solution. It also indicates that some residual water framework possibly exist in the memory water. This result is consistent with the conclusion that memory effect benefits for shortening induction time of hydrate formation.[42] Here, we propose that water molecules in residual relic framework are competed between the construction of hydrate cavities and the freezing to ice. Such competitive result leads to the memory effect and the tiny exothermic peaks as above mentioned. For each temperature increasing process, two endothermic peaks can be found, as shown in Fig. 1. The first endothermic peak with asterisk at $272.28 \mathrm{~K}$ is assigned to the ice melting, and the second endothermic peak is related to the dissociation of THF-hydrogen binary hydrate. For the ice melting, all endothermic peaks show similarly. Only the area of the endothermic peak obtained in the memory solution is a little smaller than that obtained in the fresh solution. It is another evidence for the existence of water residual relic framework in the memory solution. Moreover, the addition of THF shows a positive effect on keeping this kind of framework structure. In our previous work, the similar water aggregation was ever testified using in-situ Raman in the gas/THF solution interface and in the THF solution after hydrate dissociation. [15] For the hydrate dissociation, the area of endothermic peak obtained in the memory solution is also smaller than that in the fresh solution, showing the amount of the heat releasing from THF-hydrogen binary hydrate formation in the memory solution less than that in the 
fresh solution. Due to the same thermal state after hydrate dissociating completely, this phenomenon involves into the decrease of the water molecules which can directly form the binary hydrate from the free situation instead of the residual framework structure. On the contrary, it also indirectly illustrates that the residual framework exhausts and limits some free water molecules. According to the report, [43] the onset temperature of hydrate dissociation can be determined based on the intersection of baseline and the linear part of endothermic peaks. As shown in Fig. 3, THFhydrogen binary hydrate is dissociated at $282.18 \mathrm{~K}$ and $282.28 \mathrm{~K}$ in the fresh solution and in the memory solution, respectively. The temperature deviation of $0.1 \mathrm{~K}$ is in the range of temperature measuring error. Therefore, no obvious influence on equilibrium data is resulted in the memory solution. In sum, the memory effect really exist in the memory solution, affecting water aggregation in the process of hydrate formation and dissociation, however, it shows no significant influence on thermal state of THF-hydrogen binary hydrate.

\subsubsection{Thermal properties of THF-hydrogen binary hydrate}

Thermograms of these THF-hydrogen binary hydrates are shown in Fig. 2, and two groups of endothermic peaks can be observed. One group of endothermic peaks with asterisk are assigned to the process of ice melting, and another group of endothermic peaks are assigned to the dissociation process of THF-hydrogen binary hydrate. For the endothermic peaks relative to ice melting, it can be found that the ice melting temperature decreases with the increase of pressure, moreover, the temperature deviation among these ice melting temperatures under difference pressure are changed in the range of around $1.5 \mathrm{~K}$, higher than the temperature accuracy of $0.1 \mathrm{~K}$ for $h p$-DSC equipment. It illustrates that the crystallinity of THF-hydrogen binary hydrate can be improved through increasing pressure, weakening the degree of cementation among THF molecules and ice due to THF-hydrogen binary hydrate appearance. In detail, there are hydrogen bonding among water molecules of ice and THF molecules without hydrate formation, resulting in a higher temperature to melt this kind of ice. However, these intermolecular forces can be weaken with the decrease of THF molecules due to THF-hydrogen binary hydrate. Specially, THF molecules can be reduced significantly because most of them are encaged into hydrate cavities by enhancing the pressure. As a result, the eutectic temperature is lowered by increasing pressures. Similar conclusion was ever reported in the hydrate formation system containing water, THF and carbon dioxide.[41] For the endothermic peaks corresponding to THF-hydrogen binary hydrate, it can be found that the temperature of hydrate dissociation increases with the increase of pressures. It illustrates that thermal state of THFhydrogen binary hydrate is different under different conditions of pressure and temperature, meanwhile, the equilibrium temperature of THF-hydrogen binary hydrate increases with the increase of pressures. Because higher driving force for hydrate formation could be supplied by decreasing the temperature at the certain pressure. Besides, amplitudes of the endothermic peaks for THF-hydrogen binary hydrate dissociation are also dependent pressure. The higher pressure results in a larger endothermic peak of THF-hydrogen binary hydrate dissociation. In addition, the asymmetry of these endothermic peaks is not perfect, showing different tiny shoulder peaks under different pressures, as marked with crisscross. For example, the shoulder peak obtained at the pressure of $34.00 \mathrm{MPa}$ occurs prior to those obtained under pressures of $18.00 \mathrm{MPa}$ and $25.00 \mathrm{MPa}$. It may be resulted from the initial escaping of hydrogen molecules from hydrate cavities prior to THF molecules releasing in the process of hydrate dissociation at pressure of 
34.00 MPa. Because the cavities without trapping THF molecules may be encaged by hydrogen molecules completely, showing a flexible escaping situation for hydrogen molecules in comparison with that for THF molecules on basis of different weak intermolecular forces between cavities-hydrogen molecules and cavities-THF molecules. And it may be one reason for the decrease of ice melting temperature with the increase of pressure. More experiments need to be carried out in the future. Based on the onset point determined methods mentioned in section 3.1.1, the dissociation temperature of THF-hydrogen binary hydrate can be obtained. As shown in Fig. 2, the hydrate dissociation temperature is $282.41 \mathrm{~K}, 284.09 \mathrm{~K}$ and $285.82 \mathrm{~K}$ at the pressure of $18.00 \mathrm{MPa}, 25.00 \mathrm{MPa}$ and $34.00 \mathrm{MPa}$, respectively. Based on these data for the thermal state of THF-hydrogen binary hydrate, a elemental P-T curve can be plotted as shown in Fig. 3. For the hydrogen formation system, $h p$-DSC is a good equipment to perform the equilibrium data with extra high pressure and understand the hydrate dissociation process.

\subsection{Macroscopic kinetics and morphology during hydrate formation}

Kinetic experiments of THF-hydrogen hydrate are carried out in the 3.0 mol\% THF solution at $273.15 \mathrm{~K}$ and $14.53 \mathrm{MPa}$. Morphology of hydrate formation process were filmed by a camera. The hydrate formation rate is evaluated by an average rate, calculating with the amount of gas uptake per unit time $(\mathrm{mmol} / \mathrm{h})$. Fig. 4 shows morphology of hydrate formations at $0,48,96,127,132$ and 168 h, respectively. Fig. 5 show changes of pressure and gas uptake in the process of hydrate formation. With hydrate formation, the pressure continuously decreases, and the amount of gas uptake increase accordingly. As shown in Fig. 5, the hydrate formation process could be divided into three stages (stage A, stage B and stage C) with different hydrate formation rate. The average hydrate formation rate is approximately $0.19 \mathrm{mmol} / \mathrm{h}$, $1.25 \mathrm{mmol} / \mathrm{h}$ and $0.56 \mathrm{mmol} / \mathrm{h}$ obtained in stage $A$, stage $B$ and stage $\mathrm{C}$, respectively. Apparently, the distribution of hydrogen molecules is different in three stages. In stage $A$, the amount of gas uptake is possibly resulted from the hydrogen molecules movement from gaseous phase towards THF solution, forming hydrates together with THF molecules or wandering in the interspaces among THF hydrates by means of gas bubble. When THF hydrate could be formed at $273.15 \mathrm{~K}$, as shown in Fig. 4. At the beginning, no hydrate can be observed in gas/liquid interface. From $48 \mathrm{~h}$ to $127 \mathrm{~h}$, the obvious hydrate layer could be found, furthermore, this hydrate layer continuously thickens toward the bulk solution with time. Especially, some eye-catching gas bubbles can be observed. There are two reasons for the limited hydrate formation rate in Stage A. On the one hand, at the beginning, the amount of stable cavities is limited to hold hydrogen molecules enough. On the other hand, the mass transfer resistance from THF hydrate layer leads to the limited movements of hydrogen molecules from gaseous phase towards solution. However, due to the size of is quite small, hydrogen molecules could still move from gaseous phase towards the top of THF hydrate layer, and move among THF hydrates due to the small molecular size. From Fig. 4, some gas bubbles can be observed at $48 \mathrm{~h}$, it proves that hydrogen molecules wander in the interspaces among THF hydrates in Stage A. Subsequently, with hydrogen molecules moving among THF hydrates, some of hydrogen molecules are captured into cavities, forming THF-hydrogen binary hydrates. As a result, both of the amount of gas uptake and the hydrate formation rate sharply increase in Stage B. It is consistent with the results obtained in the system with hydrogen.[44] As hydrate cavities are encaged by hydrogen molecules in the top of THF hydrate layer, the mass transfer between free hydrogen molecules and the empty hydrate 
cavities will be limited. As a result, hydrogen molecules have to wander among THF hydrates again, encage into cavities with cluster, or move through tunnels among cavities of THF hydrates. At $127 \mathrm{~h}$ and $132 \mathrm{~h}$ in Stage B, the hydrate in the gas/liquid interface is densifying towards the bulk solution and some hydrates are growing along the crystallizer wall upper the gas/liquid interface. In the bulk solution, the transparent hydrate crystals and a clear hydrate layer boundary could be observed. It illustrates that hydrogen molecules benefits for the hydrates formation, moreover, they are helpful to accelerate the hydrate formation. Consequently, as shown in Stage $C$, the hydrate formation rate decreases again because of mass transfer resistance. But it is higher than that obtained in stage A for hydrogen molecules continuous encaging into hydrate cavities. At $168 \mathrm{~h}$, the hydrate crystals grow into the bulk solution, which is consistent with the change of gas uptake as shown in the stage C in Fig. 7. After hydrate forming $192 \mathrm{~h}$, around 0.0722 mol hydrogen is consumed and the density of hydrogen of $1.875 \mathrm{~g} /$ liter water can be obtained, which is an important parameter to estimate storage capacity for hydrate-based hydrogen storage technology.

Take the gas uptake into account, it shows that hydrogen molecules maybe also play a inducing role to accelerate the formation of the binary hydrate, like THF promoter molecules in this work. The hydrates containing hydrogen firstly form in the gas/liquid interface, then continuous nucleate and grow towards bulk solution. This kind of growth model just relates to hydrates containing gas molecules instead of the pure hydrates of promoters. As reported by Veluswamy et al.[27] and Cai et al.,[15] for the hydrogen formation system, the obvious hydrate crystal and the boundary between the hydrates and the solution can be observed in the gas/liquid interface from the pictures. On basis of enough contact among gas, hydrate promoter and water molecules, the mixed hydrate also could be formed in the bulk solution for carbon dioxide solubility in statics or stirring systems. Especially, such gas/liquid interface present between the gaseous phase and the solution by adding the hydrate promoter of THF with hydrophilic and polarity. However, for the $\mathrm{CO}_{2} / \mathrm{H}_{2}$ hydrate formation system, the hydrate crystal can be initially observed in the gas/liquid interface. This hydrate crystal growth models are due to the different solubility of $\mathrm{CO}_{2}$ molecules and hydrogen molecules not just THF molecules. Apparently, it could indirectly illustrate that the participation of the gas molecules also show a promoting effect on the mixed hydrate formation.

\subsection{Raman spectra for compounds during hydrate formation}

\subsubsection{Detail different structures during hydrate formation}

As shown in Fig.4 and Fig.5, morphology and gas uptake for THF-hydrogen hydrate formation have been obtained, and it is helpful to understand the hydrate formation process from the macroscopic point of view. However, factors affecting hydrate formation rate and distinguishing of THF hydrate and THF-hydrogen hydrate need to be clear from the microscopic point of view. Therefore, in-situ Raman spectrometer is employed to focus on microscopic information in and around gas/liquid interface and growing hydrate layer in the process of the hydrate formation.

Take Raman spectra for hydrate formation at $127 \mathrm{~h}$ as an example, Fig. 6 shows Raman spectra for compounds from gaseous phase towards THF solution at $127 \mathrm{~h}$ occurring the special pressure drop, as shown in Fig.5. The structures of compounds in gaseous phase, hydrate layer and THF solution are detailed in Fig. 6. Generally, it will involve into three 
significant signs relative to hydrate formation on Raman spectra in the system containing THF molecules and hydrogen molecules. For hydrogen molecules, Raman peaks at around $583 \mathrm{~cm}^{-1}$ (as shown in Fig. 7-11), $4126 \mathrm{~cm}^{-1}, 4144 \mathrm{~cm}^{-1}, 4155$ $\mathrm{cm}^{-1}$, and $4162 \mathrm{~cm}^{-1}$ are assigned to $\mathrm{H}-\mathrm{H}$ vibration model in gaseous phase. When hydrogen molecules are trapped into hydrate cavities, Raman peaks at around $583 \mathrm{~cm}^{-1}$ (as shown in Fig. 7-11), $4144 \mathrm{~cm}^{-1}, 4155 \mathrm{~cm}^{-1}$, and $4162 \mathrm{~cm}^{-1}$ disappear, and only a broad bands can be detected as hydrogen molecules encaged into hydrate cavities. As shown in Fig.6 (a), the peaks at around $4126 \mathrm{~cm}^{-1}$ in gaseous phase blue-shift to around $4129 \mathrm{~cm}^{-1}$ when hydrogen molecules are encaged into hydrates. Moreover, the intensity of Raman peaks corresponding to hydrogen molecules inside hydrates significantly decrease in comparison with that in gaseous phase. Such phenomenon is consistent with the results reported in literatures.[39,45] As shown in Fig. 6(b), for THF molecules, Raman peaks at around $913 \mathrm{~cm}^{-1}$ are assigned to ring breathing model, and Raman peaks at around $2889 \mathrm{~cm}^{-1}, 1948 \mathrm{~cm}^{-1}$ and $2994 \mathrm{~cm}^{-1}$ are assigned to $\mathrm{C}-\mathrm{H}$ stretching vibration model in solution. When THF molecules are trapped into hydrate cavities, the intensity of Raman peaks corresponding to $\mathrm{C}-\mathrm{H}$ stretching vibration and ring breathing model significant reduce in THF solution and into hydrate cavities in comparison with that in pure liquid THF. Especially, Raman peaks at $884 \mathrm{~cm}^{-1}$ is an important sign to distinguish the THF molecules encaged into the hydrates or not.[22] The occurring of this peak illustrates that THF molecules are surrounded by free water molecules or the unstable water fragments. Oppositely, the disappearing of this peak generally shows that THF molecules are encaged into hydrate cavities. Meanwhile, for THF molecules, the peaks at around $913 \mathrm{~cm}^{-1}$ in THF solution blue-shift to around $916 \mathrm{~cm}^{-1}$ in THF-hydrogen hydrate, which shows similar blue-shift with the results reported by Komatsu et al.[46] In this work, the peaks at around $915 \mathrm{~cm}^{-1}$ is regarded as the sign relative to the occurring of THF-hydrogen hydrate intermediate in the process of THF-hydrogen binary hydrates. From Fig. 6(b), it also can be found that Raman peaks corresponding to ring breathing of THF molecules blue-shift from $913 \mathrm{~cm}^{-1}$ to 916 $\mathrm{cm}^{-1}$, when the stable hydrate structures appear with trapping of hydrogen molecules into hydrate cavities, as shown in Fig. 6(a). Based on Raman structure changes with time, as shown in Fig. 7-11, we proposed that small hydrogen molecules have a promoting effect on binary hydrate stability. In other words, the formation of stable THF-hydrogen binary hydrates are formed based on the synergistic effect of THF molecules and hydrogen molecules. Same conclusion was ever proven based on phase equilibrium experiments carried out by Trueba et al.[47] For water molecules, Raman peaks at around $3400 \mathrm{~cm}^{-1}$ are assigned to $\mathrm{O}-\mathrm{H}$ stretching vibration in free water molecules (FW), and Raman peaks at around $3200 \mathrm{~cm}^{-1}$ are assigned to $\mathrm{O}-\mathrm{H}$ stretching vibration in water cluster with intermolecular hydrogen bonds (BW). The relative intensity $\left(I_{\mathrm{BW}} / \mathrm{I}_{\mathrm{FW}}\right)$ of the peaks at $3200 \mathrm{~cm}^{-1}$ and $3400 \mathrm{~cm}^{-1}$ is an important sign to determine hydrates formation as well. The increase of $I_{\mathrm{BW}} / \mathrm{I}_{\mathrm{FW}}$ illustrates hydrate formation due to the increase of bonding water molecules in systems, like the value of $I_{B W} / I_{F w}$ higher than 1 . To illustrate hydrate formation process at different time, Raman peaks for compounds in different phase and their intensity changes are determined and compared on basis of three different signs in section 3.3.2.

\subsection{2 in-situ Raman spectra for hydrate formation}

Fig. 7 shows Raman spectra for compounds at the beginning of hydrate formation at $273.15 \mathrm{~K}$ and $14.53 \mathrm{MPa}$. Only compounds structure in gas/liquid interface are measured. It can be found that numbers of Raman spectra is limited 
because gas/liquid interface is quite thin. In addition, the intensity of peaks are weak. It is consistent with our previous report of gas/liquid interface.[15] Three different kinds of peaks corresponding to hydrogen, THF and water molecules can be observed from Raman spectra, as detailed in Fig. 6. In Fig. 7, all peaks mentioned above in Section 3.3.1 are weak, and even some of them fail to be detected. It proves that gas/liquid interface show the special character on reducing and changing the distribution of compounds in the gas/liquid interface. Especially, in the gas/liquid interface, the water molecules are rearranged, the distribution of hydrogen molecules are changed, and the polarity of THF molecules are influenced. Moreover, the concentration of hydrogen, THF and water molecules in the gas/liquid interface is limited. As a result, there is an obvious density deviation for hydrogen, THF and water molecules relative to hydrogen in gaseous phase, THF in solution and water in bulk aqueous solution, respectively. Additionally, some relative intensity $\left(I_{\mathrm{BW}} / \mathrm{I}_{\mathrm{FW}}\right)$ of the peaks at $3200 \mathrm{~cm}^{-1}$ and $3400 \mathrm{~cm}^{-1}$ corresponding to water molecules is marked in Fig. 7. It can be found that most of values of $\mathrm{I}_{\mathrm{BW}} / \mathrm{I}_{\mathrm{FW}}$ are less than 1 in THF solution, related to free water molecules. However, some values of $\mathrm{I}_{\mathrm{BW}} / \mathrm{I}_{\mathrm{FW}}$ are more than 1, related to the bonding water molecules. Moreover, such distribution of relative intensities shows irregularly, it illustrates that the water molecule aggregate around the gas/liquid interface are changed. Moreover, the water molecules in and around the interface mainly shows the similar characteristics of bonding water molecules in hydrates. Therefore, it verifies that the gas/liquid interface has a positive effect on constructing water clusters or water framework initially in THF solution.

Fig. 8 shows Raman spectra for compounds in the process of the hydrate formation at $48 \mathrm{~h}$. As shown in Fig. 5 and Fig.6, gas uptake and observable hydrate crystals show that hydrates are forming with time. However, it is difficult to determine the situation of hydrogen molecules, drifting among THF hydrate or encaging into hydrate cavities. From Fig. 8 , it can be found that only one broad peak for hydrogen molecules could be detected at around $4129 \mathrm{~cm}^{-1}$, corresponding to hydrogen molecules encaged into hydrate cavities. As reported in the literature,[48] this peak of hydrogen molecules is blue-shifted from Raman peaks at around $4126 \mathrm{~cm}^{-1}$ corresponding to $\mathrm{H}-\mathrm{H}$ vibration model in gaseous phase due to the electron density of hydrogen molecules affected by water molecules. Moreover, the intensity of broad peaks at around $4129 \mathrm{~cm}^{-1}$ are significantly decreased in comparison with those in gaseous phase. In addition, for THF molecules, the peaks at around $913 \mathrm{~cm}^{-1}$ corresponding to ring breathing vibration in solution blue-shifts to 916 $\mathrm{cm}^{-1}$, and the peaks at around $884 \mathrm{~cm}^{-1}$ disappear, as shown in part a and part b of Fig. 8 . It means that THF molecules are always trapped into hydrate cavities. For most of Raman peaks for water molecules, the values of relative intensity $\left(\mathrm{I}_{\mathrm{BW}} / \mathrm{I}_{\mathrm{FW}}\right)$ of the peaks at $3200 \mathrm{~cm}^{-1}$ and $3400 \mathrm{~cm}^{-1}$ corresponding to water molecules are more than 1 , it is related to bonding water molecules for constructing hydrate cavities. In addition, the broad peak at $4129 \mathrm{~cm}^{-1}$ corresponding to hydrogen molecules encaged into hydrates shows a regular trends from the gas/liquid interface towards the lower boundary of the hydrate layer, especially as shown in part b in Fig. 8. Moreover, as shown in part a in Fig. 8, water molecules shows bonding water molecules, but there is no obvious hydrogen molecules can be found. It illustrates that hydrogen molecules continuously move from the interspace among hydrates formed in the gas/liquid interface towards THF hydrates. Moreover, this kind of hydrogen molecules movement of among the hydrates has no effect on the hydrate structures at $48 \mathrm{~h}$. 
Fig. 9 shows Raman spectra for compounds in the process of the hydrate formation at $96 \mathrm{~h}$. As detailed in part a, for THF molecule, the peaks at around $884 \mathrm{~cm}^{-1}$ appears, and no obvious peaks corresponding to hydrogen molecules encaged into hydrate cavities can be observed. Although some peaks corresponding to bonding water are still shown in this part, the relative intensity $\left(I_{\mathrm{BW}} / \mathrm{I}_{\mathrm{FW}}\right)$ of the peaks at $3200 \mathrm{~cm}^{-1}$ and $3400 \mathrm{~cm}^{-1}$ corresponding to water molecules apparently decrease. Especially, most of values of $\mathrm{I}_{\mathrm{BW}} / \mathrm{I}_{\mathrm{FW}}$ are less than 1 . It shows that hydrogen molecules is still moving from hydrate cavities towards hydrate layer, as illustrated in Fig. 6. Moreover, with this movement of hydrogen molecules, the hydrate cavities are destroyed, and THF molecules release from hydrates after a long time due to the occurrence of the peaks at around $884 \mathrm{~cm}^{-1}$. In other words, it indirectly proves that hydrogen molecules has a positive effect on binary hydrate stability. However, in the middle hydrate layer as shown in part b, the peaks hydrogen molecules encaged into hydrate cavities can be observed again, and relative intensity $\left(I_{\mathrm{BW}} / \mathrm{I}_{\mathrm{FW}}\right)$ of the peaks at $3200 \mathrm{~cm}^{-1}$ and $3400 \mathrm{~cm}^{-1}$ corresponding to water molecules increase as well, and the values of $\mathrm{I}_{\mathrm{BW}} / \mathrm{I}_{\mathrm{FW}}$ are higher than 1 . As shown in part $b$, there are only one peaks at around $916 \mathrm{~cm}^{-1}$ corresponding to THF molecules encaged into hydrate cavities. Therefore, we proposed that hydrogen molecules tunnel among hydrate cavities in hydrate layer, which is consistent with the results shown in Fig. 8. This is first time to illustrate the tunneling movement of hydrogen molecules in liquid systems. Same hydrogen molecules tunneling among water cavities was were reported in solid systems by Belosudov et al.[10] Based on the results of lattice dynamic and molecular dynamic, hydrogen molecules could move from the cavities of $I_{h}$ ice towards the hydrate/ice interface, further encaged into hydrate cavities and forming hydrogen hydrates. Due to the encaging of hydrogen molecules, THF hydrate become more stable. Because of these intrinsic structures changes, the rate of gas uptake is limited in Stage A, as shown in Fig.6. From morphology of hydrate formation at $48 \mathrm{~h}$ and $127 \mathrm{~h}$, gas bubble surrounded by hydrates disappeared because of THF-hydrogen binary hydrate formation. It also another indirect evidence for hydrogen molecules are moving among hydrates and tunneling through hydrate cavities in Stage A.

Fig.10 shows Raman spectra for compounds in the process of the hydrate formation at $132 \mathrm{~h}$. From the gas/liquid interface toward the lower boundary of hydrate layer, the peaks at around $916 \mathrm{~cm}^{-1}$ corresponding to THF molecules encaged into hydrate cavities and the broad peaks at around $4129 \mathrm{~cm}^{-1}$ corresponding to hydrogen molecules encaged into hydrate cavities are increase again in comparison with those at $96 \mathrm{~h}$. Moreover, the relative intensity $\left(\mathrm{l}_{\mathrm{BW}} / \mathrm{I}_{\mathrm{FW}}\right)$ of the peaks at $3200 \mathrm{~cm}^{-1}$ and $3400 \mathrm{~cm}^{-1}$ corresponding to water molecules apparently increase. These prove that the stable THF-hydrogen binary hydrates are formed at $132 \mathrm{~h}$, and more hydrogen molecules can be encaged into hydrate cavities as well. It is consistent with macroscopic results based on gas uptakes change as shown in Fig. 6 . The rate of gas uptake increases, resulting from the rearrangement of THF molecules and hydrogen molecules in hydrate cavities at $132 \mathrm{~h}$, further affecting THF-hydrogen binary hydrate formation. After the rearrangement of THF molecules and hydrogen molecules, the regular structure changes at $168 \mathrm{~h}$ can be found as shown in Fig. 11. As shown in part a, the broad peaks at around $4129 \mathrm{~cm}^{-1}$ corresponding to hydrogen molecules encaged into hydrate cavities show an obvious distribution change from the gas/liquid interface towards the bulk hydrate layer. As detailed in part a and part $b$, all relative intensity $\left(\mathrm{l}_{\mathrm{BW}} / \mathrm{I}_{\mathrm{FW}}\right)$ of the peaks at $3200 \mathrm{~cm}^{-1}$ and $3400 \mathrm{~cm}^{-1}$ corresponding to water molecules apparently increase. Moreover, all peaks of THF molecules appears at around $916 \mathrm{~cm}^{-1}$, presenting THF molecules encaged into the hydrates 
thanks to hydrogen molecules. It illustrates that table THF-hydrogen binary hydrate are formed in part a. However, in part $b$, only pure THF hydrates cavities need to be encaged by hydrogen molecules, or the amount of hydrogen molecules encaged into the hydrates is limited, failing to be detected. Same trend of Raman spectra at $168 \mathrm{~h}$, as shown in Fig. S4, can be found with that at $132 \mathrm{~h}$ because there is no special hydrate formation after Stage B.

\section{Conclusion}

To develop new environment-friendly methods of hydrogen storage, hydrate-based hydrogen storage was investigated in THF solution. Moreover, in order to understand aggregations of compounds in and around the gas/liquid interface, and figure out some factors relative to hydrate nucleation, two different groups of experiments were carried out in this work. Thermal properties of binary hydrates was measured by high pressure differential scanning calorimeter (hp-DSC). Gas uptake, morphology and structure changes of compounds from gas/liquid interface towards hydrate layer, were monitored by camera and in-situ Raman spectrometer in the process of the hydrate formation at $273.15 \mathrm{~K}$ and 14.53 $\mathrm{MPa}$. For thermal experiments, the dissociation temperatures of THF-hydrate binary hydrate are obtained as 282.41 K, 284.09 K and 285.82 K at the pressures of 18.00 MPa, 25.00 MPa and 34.00 MPa, respectively. During hydrate formation, hydrate nucleation initially happens in gas/liquid interface, and the aggregate of water molecules and the interaction forces among hydrogen, THF and water are significantly changed around the gas/liquid interface. This water molecules aggregate is the original structures related to hydrate nucleation. Moreover, a special pressure drop and structure change are observed at $127 \mathrm{~h}$. THF hydrates with unstable structure are found, and hydrogen molecules have positive effect on THF hydrates to be stable. The hydrogen molecules encaged into the cavities maybe move in tunnels among cavities during binary hydrate formation. For hydrate-based on hydrogen storage, the density of hydrogen with $1.875 \mathrm{~g} /$ liter water is obtained after $168 \mathrm{~h}$, and it shows a great promising competitiveness for hydrogen storage.

\section{Acknowledgements}

This work was supported by Key Program of National Natural Science Foundation of China (51736009), Special Project for Marine Economy Development of Guangdong Province (GDME-2018d002), National Science Fund for International S\&T Cooperation Program of China (2015DFA61790), National Key Research and Development Plan of China (2016YFC0304002, 2017YFC0307306), Science and Technology Apparatus Development Program of the Chinese Academy of Sciences (YZ201619), Frontier Sciences Key Research Program of the Chinese Academy of Sciences (QYZDJSSW-JSC033) and China Scholarship Council (CSC).

\section{References}

[1] Englezos P. Clathrate Hydrates. Ind Eng Chem Res 1993. doi:10.1021/ie00019a001.

[2] Sloan ED, Koh CA. Hydrate Formation and Dissociation Processes. Clathrate hydrates Nat. gases, 2008. doi:doi:10.1201/9781420008494.ch3.

[3] Chatti I, Delahaye A, Fournaison L, Petitet JP. Benefits and drawbacks of clathrate hydrates: A review of their areas of interest. Energy Convers Manag 2005. doi:10.1016/j.enconman.2004.06.032. 
[4] Eberle U, Felderhoff M, Schüth F. Chemical and physical solutions for hydrogen storage. Angew Chemie - Int Ed 2009. doi:10.1002/anie.200806293.

[5] Tranchemontagne DJ, Park KS, Furukawa H, Eckert J, Knobler CB, Yaghi OM. Hydrogen storage in new metalorganic frameworks. J Phys Chem C 2012. doi:10.1021/jp302356q.

[6] Liu C, Li F, Lai-Peng M, Cheng HM. Advanced materials for energy storage. Adv Mater 2010. doi:10.1002/adma.200903328.

[7] da Rosa A. Hydrogen Storage. Fundam. Renew. Energy Process., 2013. doi:10.1016/B978-0-12-397219-4.00011-4.

[8] Song Y. New perspectives on potential hydrogen storage materials using high pressure. Phys Chem Chem Phys 2013;15:14524-47. doi:10.13292/j.1000-4890.201601.033.

[9] Mao WL, Mao H. Hydrogen storage in molecular compounds. PNAS 2004. doi:10.1073/pnas.0307449100.

[10] Belosludov R V., Bozhko YY, Zhdanov RK, Subbotin OS, Kawazoe Y, Belosludov VR. Hydrogen hydrates: Equation of state and self-preservation effect. Fluid Phase Equilib 2016;413:220-8. doi:10.1016/j.fluid.2015.11.031.

[11] Li X Sen, Xu CG, Chen ZY, Wu HJ. Hydrate-based pre-combustion carbon dioxide capture process in the system with tetra-n-butyl ammonium bromide solution in the presence of cyclopentane. Energy 2011. doi:10.1016/j.energy.2011.01.034.

[12] Zheng J, Zhang P, Linga P. Semiclathrate hydrate process for pre-combustion capture of CO2at near ambient temperatures. Appl Energy 2017. doi:10.1016/j.apenergy.2016.10.118.

[13] Li X Sen, Xu CG, Chen ZY, Cai J. Synergic effect of cyclopentane and tetra-n-butyl ammonium bromide on hydratebased carbon dioxide separation from fuel gas mixture by measurements of gas uptake and X-ray diffraction patterns. Int J Hydrogen Energy 2012. doi:10.1016/j.ijhydene.2011.09.053.

[14] Kim SM, Lee JD, Lee HJ, Lee EK, Kim Y. Gas hydrate formation method to capture the carbon dioxide for precombustion process in IGCC plant. Int J Hydrogen Energy 2011. doi:10.1016/j.ijhydene.2010.09.062.

[15] Cai J, Zhang Y, Xu CG, Xia ZM, Chen ZY, Li X Sen. Raman spectroscopic studies on carbon dioxide separation from fuel gas via clathrate hydrate in the presence of tetrahydrofuran. Appl Energy 2018. doi:10.1016/j.apenergy.2018.01.055.

[16] Luo Y, Liu A, Guo X, Sun Q, Yang L. Experiment on the continuous recovery of H2from hydrogenation plant off-gas via hydrate formation in tetra-n-butyl ammonium bromide solution. Int J Hydrogen Energy 2015;40:16248-55. doi:10.1016/j.ijhydene.2015.09.120.

[17] John VT, Kamath VA, Malekar S. Formation of Clathrate Hydrates in Hydrogen-Rich Gases. Ind Eng Chem Process Des Dev 1983. doi:10.1021/i200020a029. 
[18] Vos WL, Finger LW, Hemley RJ, Mao HK. Novel H2-H2O clathrates at high pressures. Phys Rev Lett 1993. doi:10.1103/PhysRevLett.71.3150.

[19] Mao WL, Mao H, Goncharov AF, Struzhkin V V, Guo Q, Hu J et al.. Hydrogen Clusters in Clathrate Hydrate ( Science ) 2002. Science (80- ) 2002;297:2247-50. doi:10.1126/science.1075394.

[20] Lu H, Wang J, Liu C, Ratcliffe Cl, Becker U, Kumar R et al.. Multiple H2occupancy of cages of clathrate hydrate under mild conditions. J Am Chem Soc 2012. doi:10.1021/ja303222u.

[21] Hester KC, Strobel TA, Sloan ED, Koh CA, Huq A, Schultz AJ. Molecular hydrogen occupancy in binary THFH2clathrate hydrates by high resolution neutron diffraction. J Phys Chem B 2006. doi:10.1021/jp063164w.

[22] Florusse LJ, Peters CJ, Schoonman J, Hester KC, Koh CA, Dec SF et al.. Stable low-pressure hydrogen clusters stored in a binary clathrate hydrate. Science (80- ) 2004. doi:10.1126/science.1102076.

[23] Strobel TA, Hester KC, Sloan ED, Koh CA. A hydrogen clathrate hydrate with cyclohexanone: Structure and stability. J Am Chem Soc 2007. doi:10.1021/ja072074h.

[24] Qin Y, Du QS, Xie NZ, Li JX, Huang RB. Exploring the possibility to store the mixed oxygen-hydrogen cluster in clathrate hydrate in molar ratio 1:2 (O2 + 2H2). J Mol Graph Model 2017. doi:10.1016/j.jmgm.2017.01.001.

[25] Veluswamy HP, Chin WI, Linga P. ScienceDirect Clathrate hydrates for hydrogen storage : The impact of tetrahydrofuran, tetra-n- butylammonium bromide and cyclopentane as promoters on the macroscopic kinetics. Int J Hydrogen Energy 2014;39:16234-43. doi:10.1016/j.ijhydene.2014.01.054.

[26] Veluswamy HP, Yew JC, Linga P. New hydrate phase equilibrium data for two binary gas mixtures of hydrogen and propane coupled with a kinetic study. J Chem Eng Data 2015;60:228-37. doi:10.1021/je500489d.

[27] Veluswamy HP, Chen JY, Linga P. Surfactant effect on the kinetics of mixed hydrogen/propane hydrate formation for hydrogen storage as clathrates. Chem Eng Sci 2015;126:488-99. doi:10.1016/j.ces.2014.12.052.

[28] Jianwei D, Deqing L, Dongliang L, Xinjun L. Experimental determination of the equilibrium conditions of binary gas hydrates of cyclopentane + oxygen, cyclopentane + nitrogen, and cyclopentane + hydrogen. Ind Eng Chem Res 2010;49:11797-800. doi:10.1021/ie101339j.

[29] Sugahara T, Prasad PSR, Sloan ED, Sum AK, Koh CA, Ohgaki K. Large-cage occupancy of molecular hydrogen in binary clathrate hydrates dependent on pressure. Phys Chem Ice 2010 2011:117-25.

[30] Aladko EY, Larionov EG, Rodionova T V., Aladko LS, Manakov AY. Double clathrate hydrates of tetrabutylammonium fluoride + helium, neon, hydrogen and argon at high pressures. J Incl Phenom Macrocycl Chem 2010;68:381-6. doi:10.1007/s10847-010-9797-1.

[31] Zhang Q, Chen GJ, Huang Q, Sun CY, Guo XQ, Ma QL. Hydrate formation conditions of a hydrogen + methane gas 
mixture in tetrahydrofuran + water. J Chem Eng Data 2005;50:234-6. doi:10.1021/je0497146.

[32] Deschamps J, Dalmazzone D. Hydrogen storage in semiclathrate hydrates of tetrabutyl ammonium chloride and tetrabutyl phosphonium bromide. J Chem Eng Data 2010;55:3395-9. doi:10.1021/je100146b.

[33] Martín Á, Peters CJ. Hydrogen storage in sH clathrate hydrates: Thermodynamic model. J Phys Chem B 2009;113:7558-63. doi:10.1021/jp8074578.

[34] Arjmandi M, Chapoy A, Tohidi B. Equilibrium data of hydrogen, methane, nitrogen, carbon dioxide, and natural gas in semi-Clathrate hydrates of tetrabutyl ammonium bromide. J Chem Eng Data 2007;52:2153-8. doi:10.1021/je700144p.

[35] Tsuda T, Ogata K, Hashimoto S, Sugahara T, Moritoki M, Ohgaki K. Storage capacity of hydrogen in tetrahydrothiophene and furan clathrate hydrates. Chem Eng Sci 2009;64:4150-4. doi:10.1016/j.ces.2009.06.018.

[36] Prasad PSR, Sugahara T, Sum AK, Sloan ED, Koh CA. Hydrogen storage in double clathrates with tert-butylamine. J Phys Chem A 2009;113:6540-3. doi:10.1021/jp9029997.

[37] Zhao WH, Bai J, Wang L, Yuan LF, Yang J, Francisco JS et al.. Formation of bilayer clathrate hydrates. J Mater Chem A 2015;3:5547-55. doi:10.1039/c4ta06857b.

[38] Lim D, Park S, Ro H, Shin K, Lee H. Effect of guest-host hydrogen bonding on thermodynamic stability of clathrate hydrates: Diazine isomers. J Phys Chem C 2015;119:10218-26. doi:10.1021/acs.jpcc.5b01101.

[39] Park S, Koh DY, Kang H, Lee JW, Lee H. Effect of molecular nitrogen on multiple hydrogen occupancy in clathrate hydrates. J Phys Chem C 2014;118:20203-8. doi:10.1021/jp5061254.

[40] Mu L, von Solms N. Hydrate thermal dissociation behavior and dissociation enthalpies in methane-carbon dioxide swapping process. J Chem Thermodyn 2018. doi:10.1016/j.jct.2017.08.018.

[41] Delahaye A, Fournaison L, Marinhas S, Chatti I, Petitet JP, Dalmazzone D等. Effect of THF on equilibrium pressure and dissociation enthalpy of CO 2 hydrates applied to secondary refrigeration. Ind Eng Chem Res 2006;45:391-7. doi:10.1021/ie050356p.

[42] Li X Sen, Cai J, Chen ZY, Xu CG. Hydrate-based methane separation from the drainage coal-bed methane with tetrahydrofuran solution in the presence of sodium dodecyl sulfate. Energy and Fuels 2012. doi:10.1021/ef201804d.

[43] Du J, Wang L, Liang D, Li D. Phase equilibria and dissociation enthalpies of hydrogen semi-clathrate hydrate with tetrabutyl ammonium nitrate. J Chem Eng Data 2012. doi:10.1021/je201177t.

[44] Li ZY, Xia ZM, Chen ZY, Li X Sen, Xu CG, Yan R. The plateau effects and crystal transition study in Tetrahydrofuran (THF)/CO2/H2 hydrate formation processes. Appl Energy 2019. doi:10.1016/j.apenergy.2018.12.080. 
[45] Hashimoto S, Tsuda T, Ogata K, Sugahara T, Inoue Y, Ohgaki K. Thermodynamic Properties of Hydrogen + Tetra$<$ math $><\mathrm{mi}>\mathrm{n}</ \mathrm{mi}></$ math $>$-Butyl Ammonium Bromide Semi-Clathrate Hydrate. J Thermodyn 2010;2010:1-5. doi:10.1155/2010/170819.

[46] Komatsu H, Yoshioka H, Ota M, Sato Y, Watanabe M, Smith RL et al.. Phase equilibrium measurements of hydrogen-tetrahydrofuran and hydrogen-cyclopentane binary clathrate hydrate systems. J Chem Eng Data 2010. doi:10.1021/je900767h.

[47] Trueba AT, Rovetto LJ, Florusse LJ, Kroon MC, Peters CJ. Phase equilibrium measurements of structure II clathrate hydrates of hydrogen with various promoters. Fluid Phase Equilib 2011;307:6-10. doi:10.1016/j.fluid.2011.04.025.

[48] Lee H, Lee JW, Kim DY, Park J, Seo YT, Zeng H et al.. Tuning clathrate hydrates for hydrogen storage. Nature 2005. doi:10.1038/nature03457. 
Tables and Figures

Fig. 1. Thermograms of THF-hydrogen binary hydrate formation and dissociation at 18.00 MPa in the fresh solution and the memory solution.

Fig. 2. Thermograms of THF- hydrogen binary hydrate dissociation at different pressures.

Fig. 3. Dissociation equilibrium data of THF- hydrogen binary hydrate.

Fig. 4. Morphology at different time in the process of hydrate formation.

Fig. 5. Changes of pressure and gas uptake in the process of hydrate formation.

Fig. 6 Raman spectra for compounds from gas/liquid interface towards hydrate layer at $127 \mathrm{~h}$.

Fig. 7 Raman spectra for compounds in gas/liquid interface at the beginning.

Fig. 8 Raman spectra for compounds from gas/liquid interface towards hydrate layer at $48 \mathrm{~h}$.

Fig. 9 Raman spectra for compounds from gas/liquid interface towards hydrate layer at $96 \mathrm{~h}$.

Fig. 10 Raman spectra for compounds from gas/liquid interface towards hydrate layer at $132 \mathrm{~h}$. 


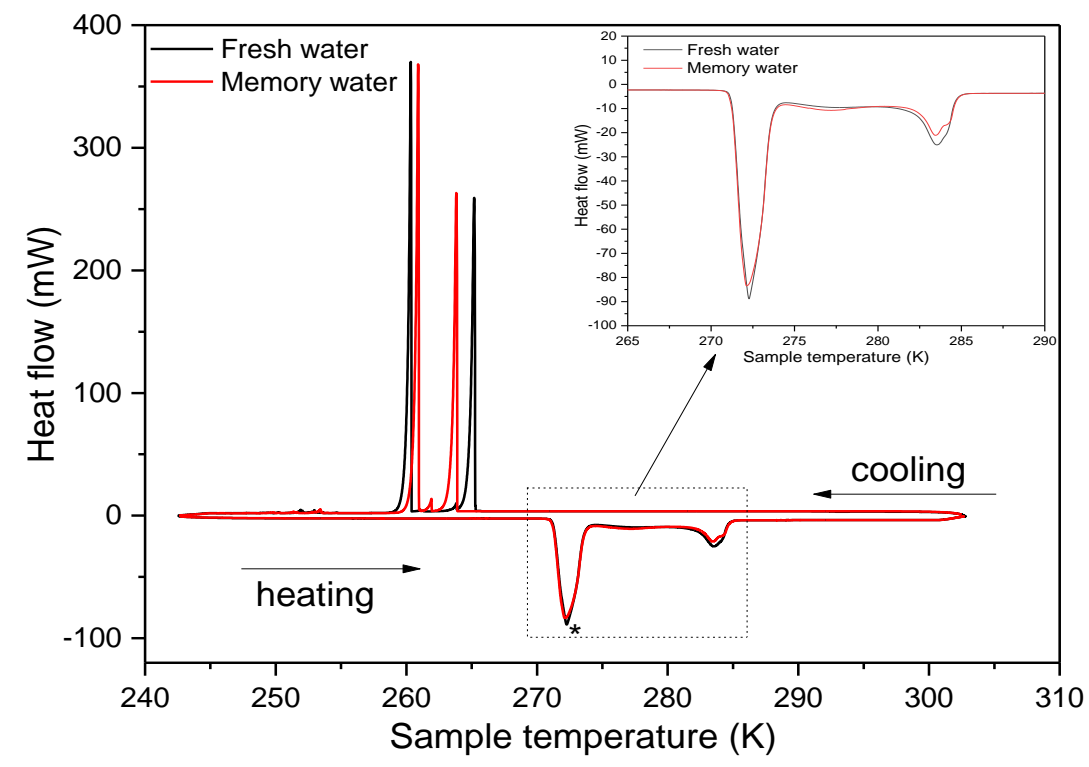

Fig. 1. Thermograms of THF-hydrogen binary hydrate formation and dissociation at $18.00 \mathrm{MPa}$ in the fresh solution and the memory solution.

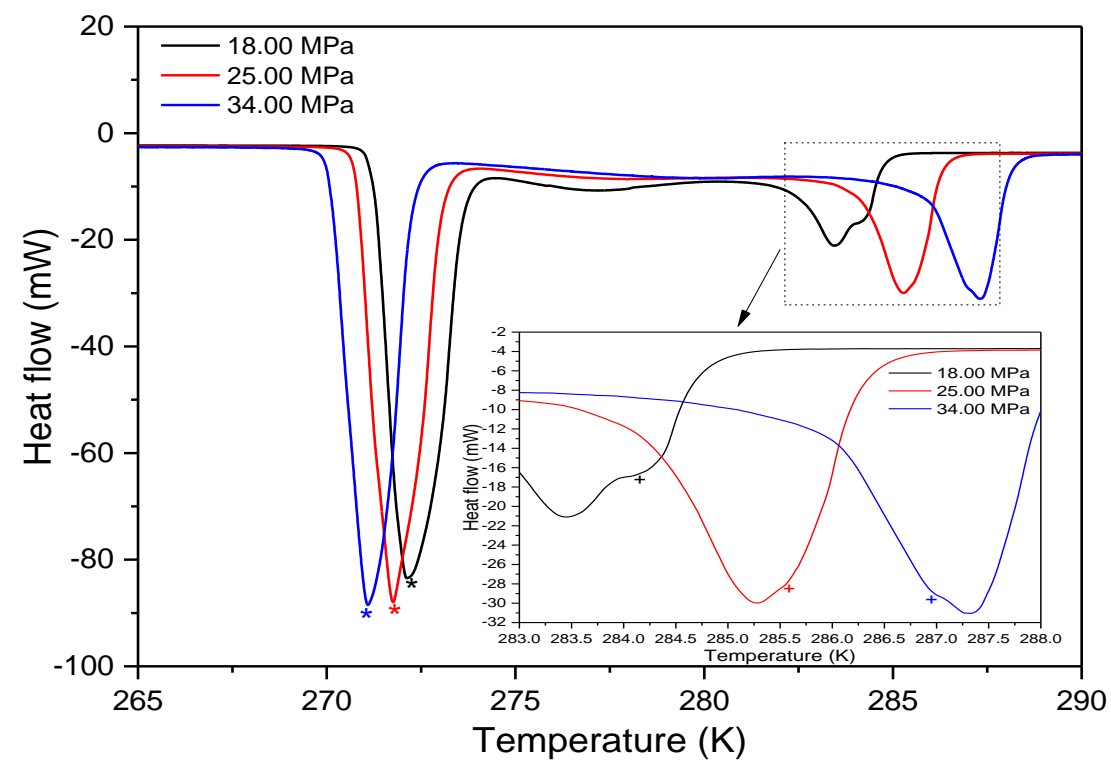

Fig. 2. Thermograms of THF- hydrogen binary hydrate dissociation at different pressures. 


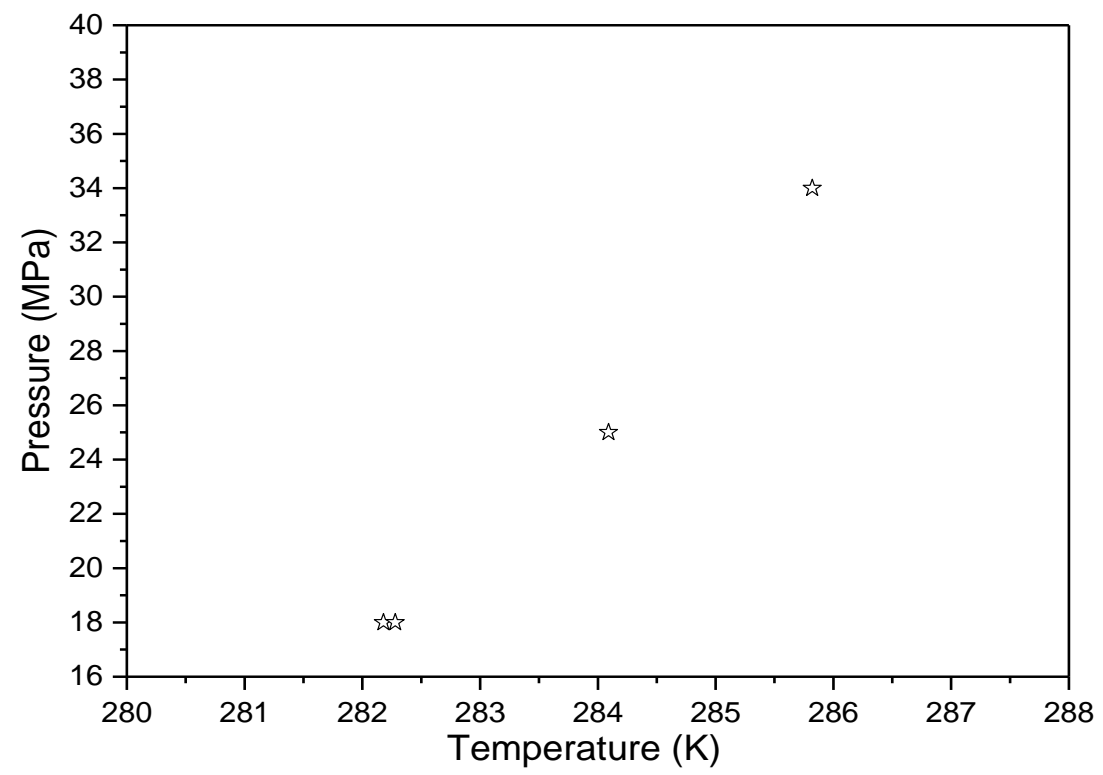

Fig. 3. Dissociation equilibrium data of THF- hydrogen binary hydrate.

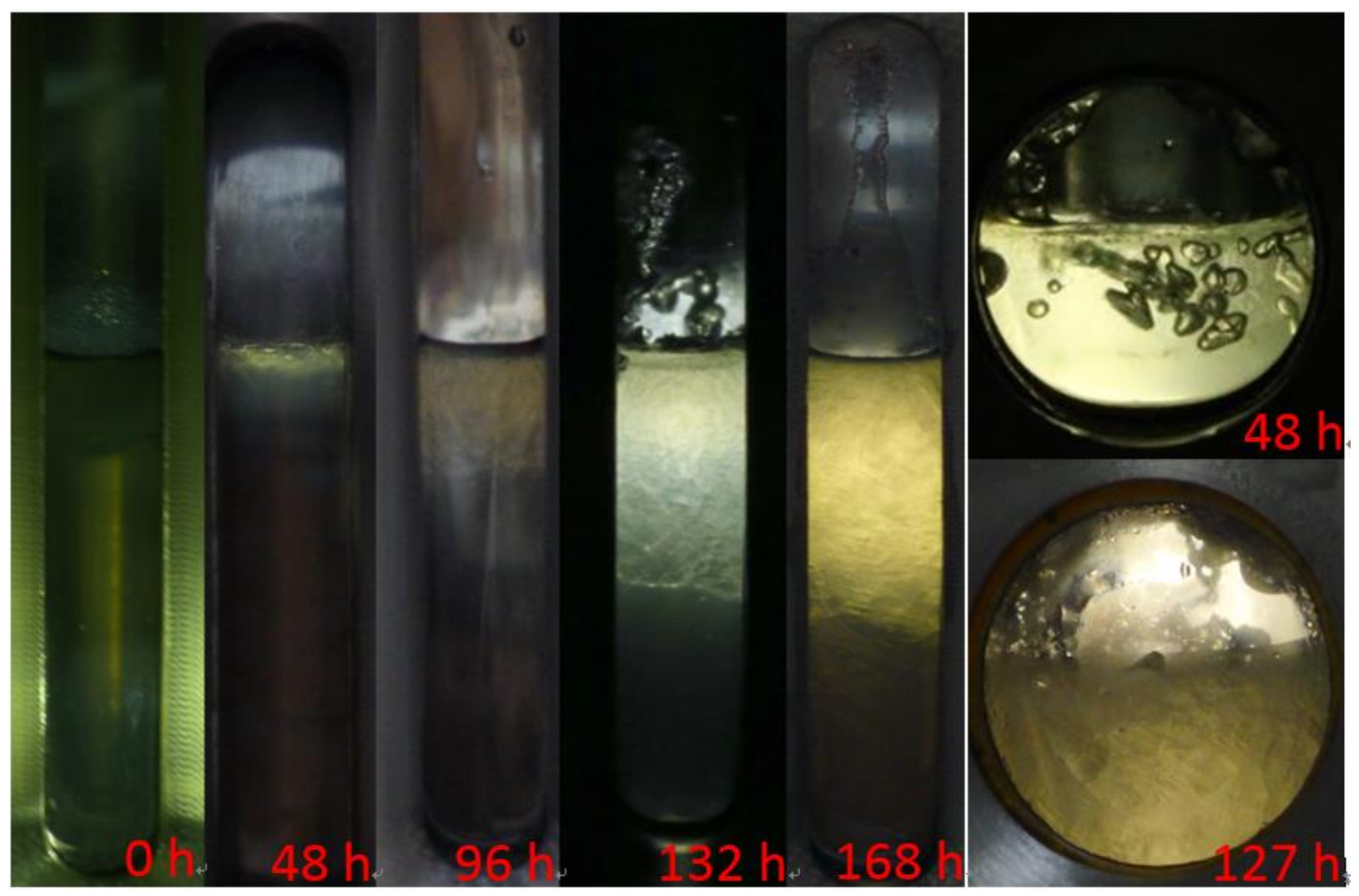

Fig. 4. Morphology at different time in the process of hydrate formation. 


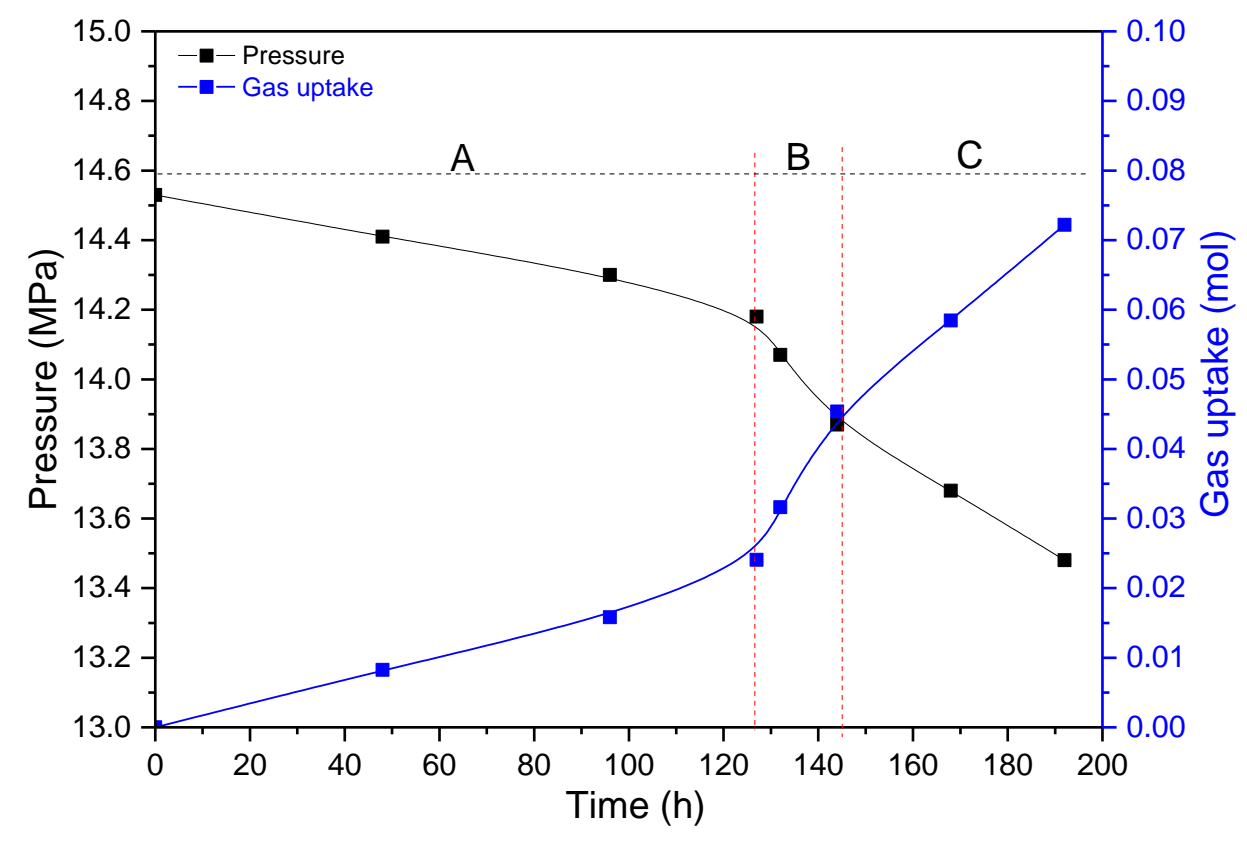

Fig. 5. Changes of pressure and gas uptake in the process of hydrate formation.

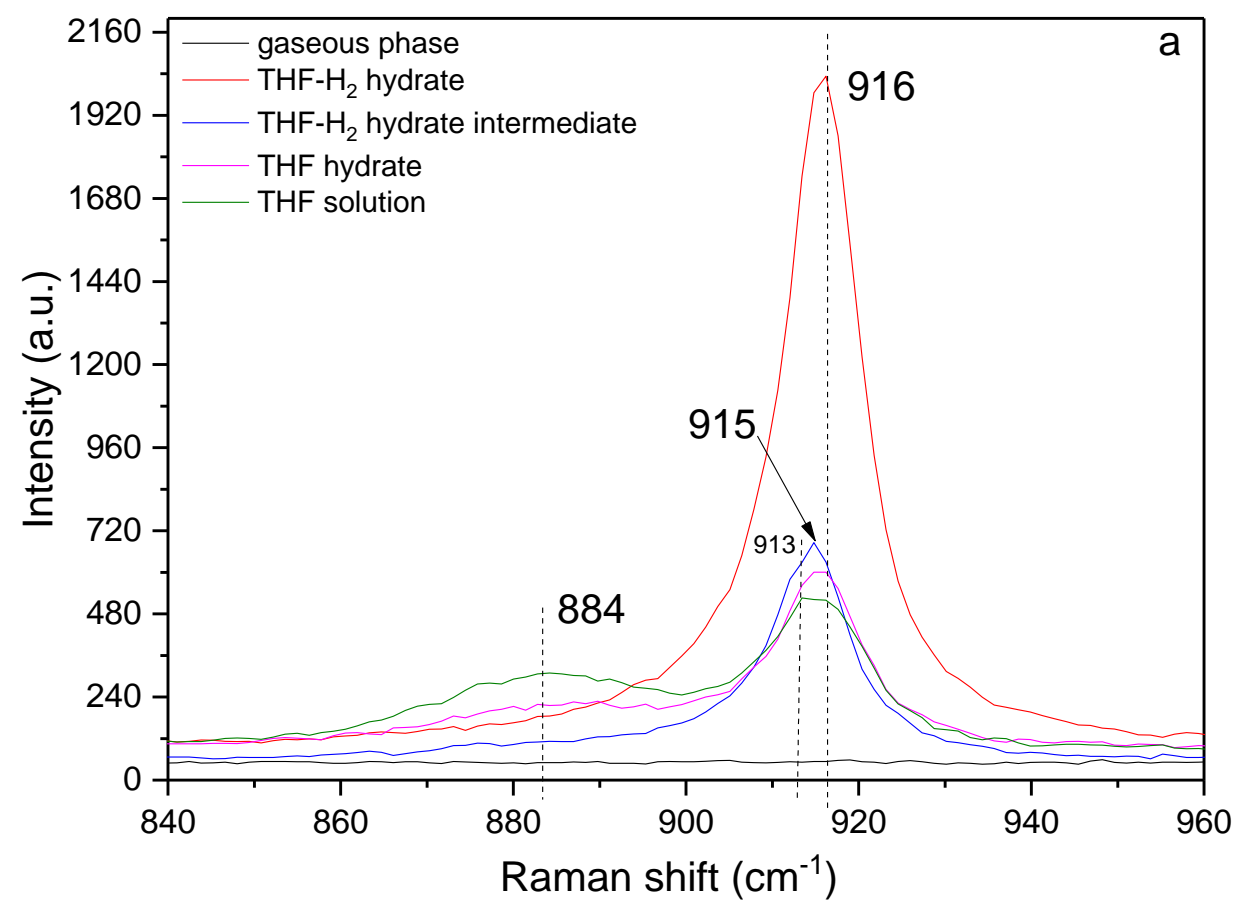



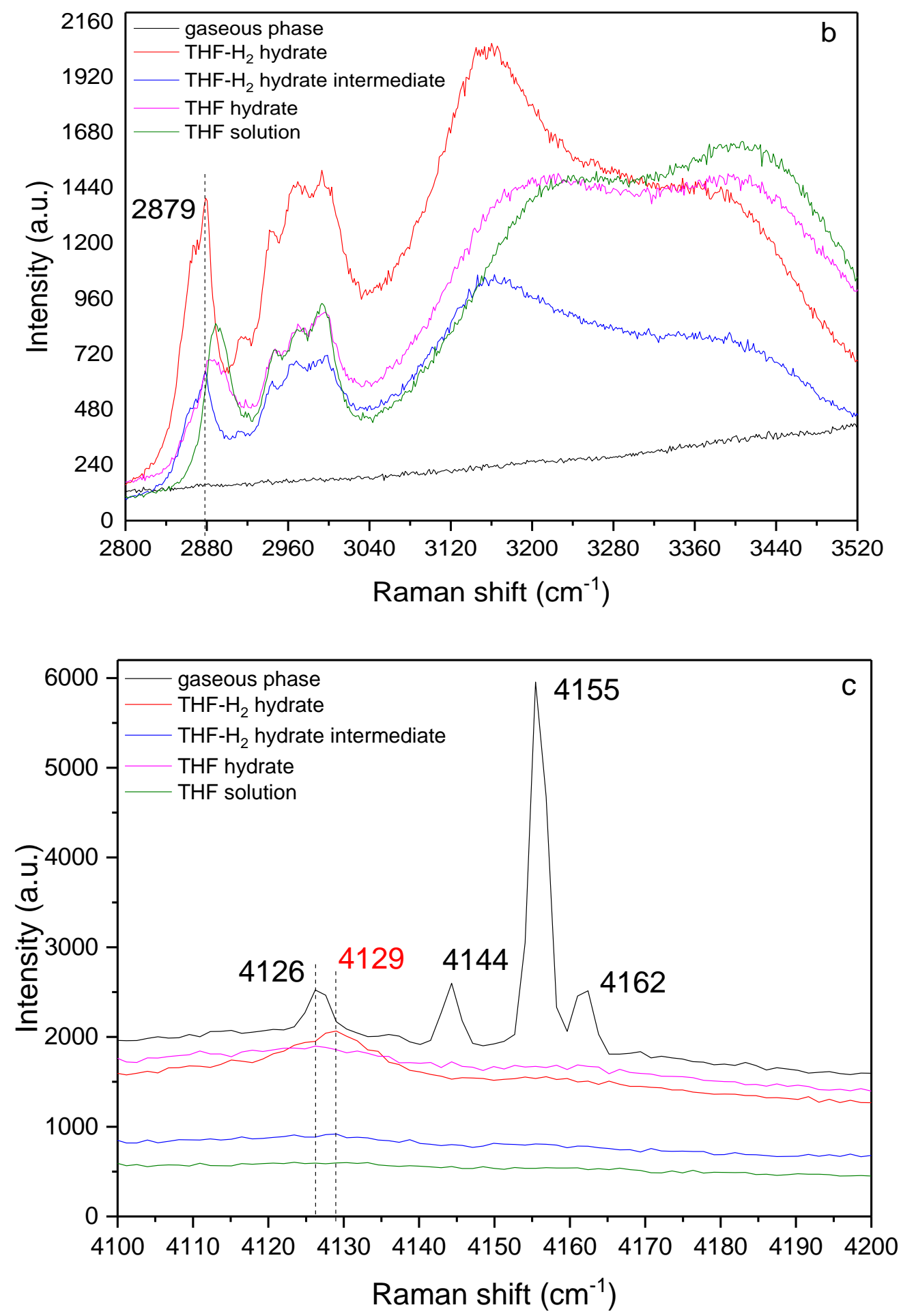

Fig. 6 Raman spectra for compounds from gas/liquid interface towards hydrate layer at $127 \mathrm{~h}$. 


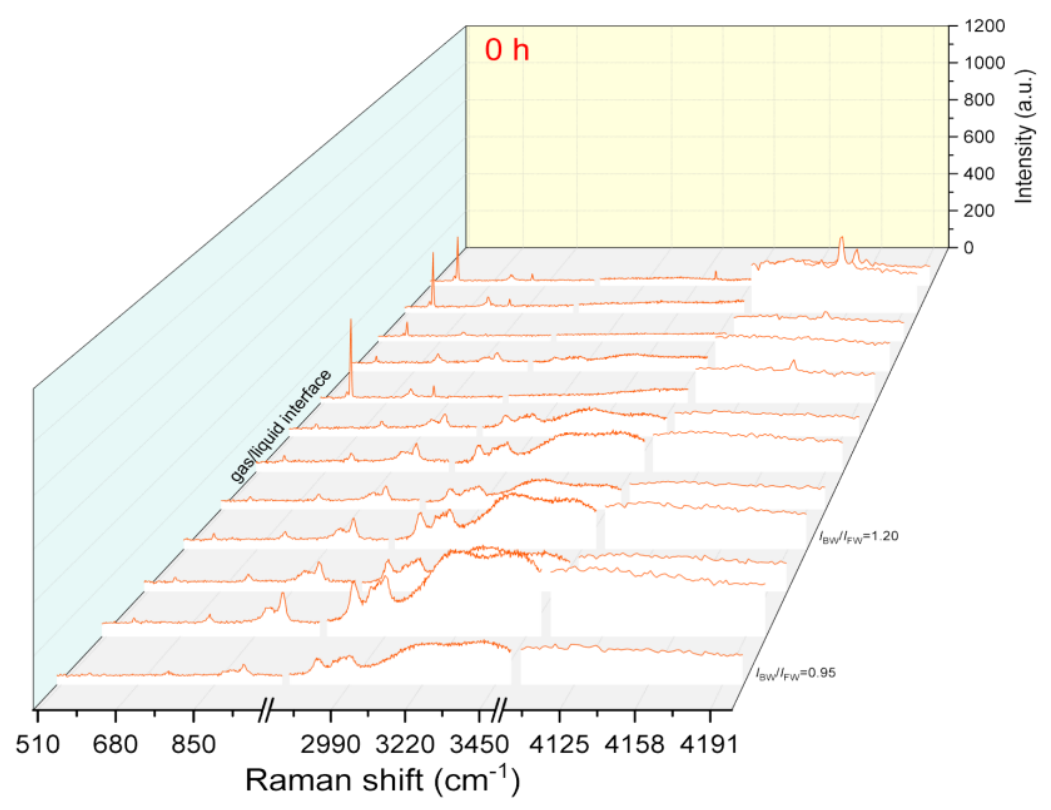

Fig. 7 Raman spectra for compounds in gas/liquid interface at the beginning.

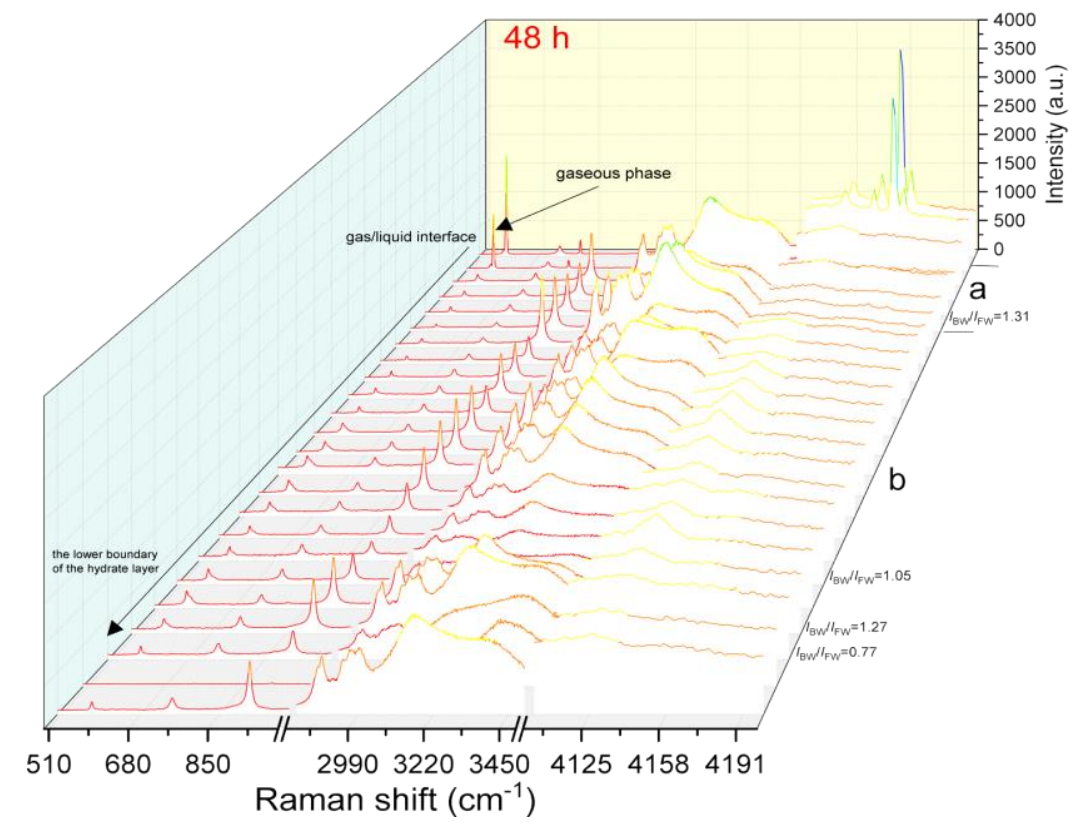

Fig. 8 Raman spectra for compounds from gas/liquid interface towards hydrate layer at $48 \mathrm{~h}$. 


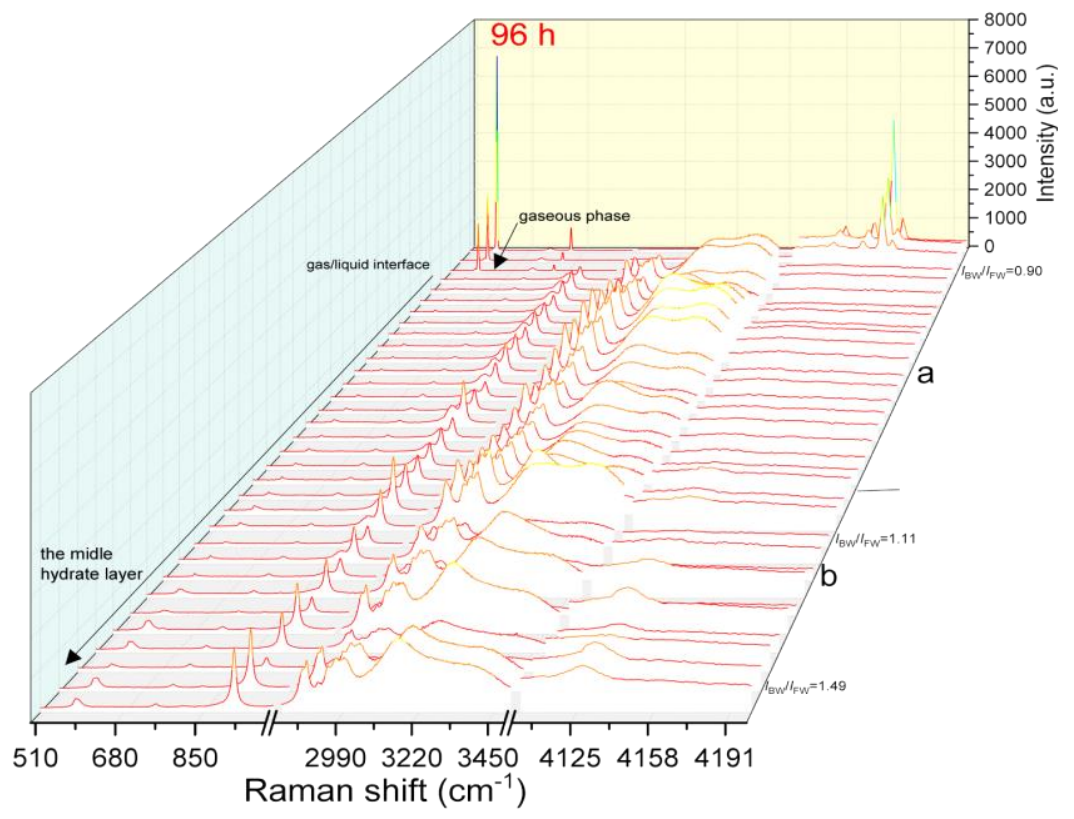

Fig. 9 Raman spectra for compounds from gas/liquid interface towards hydrate layer at $96 \mathrm{~h}$.

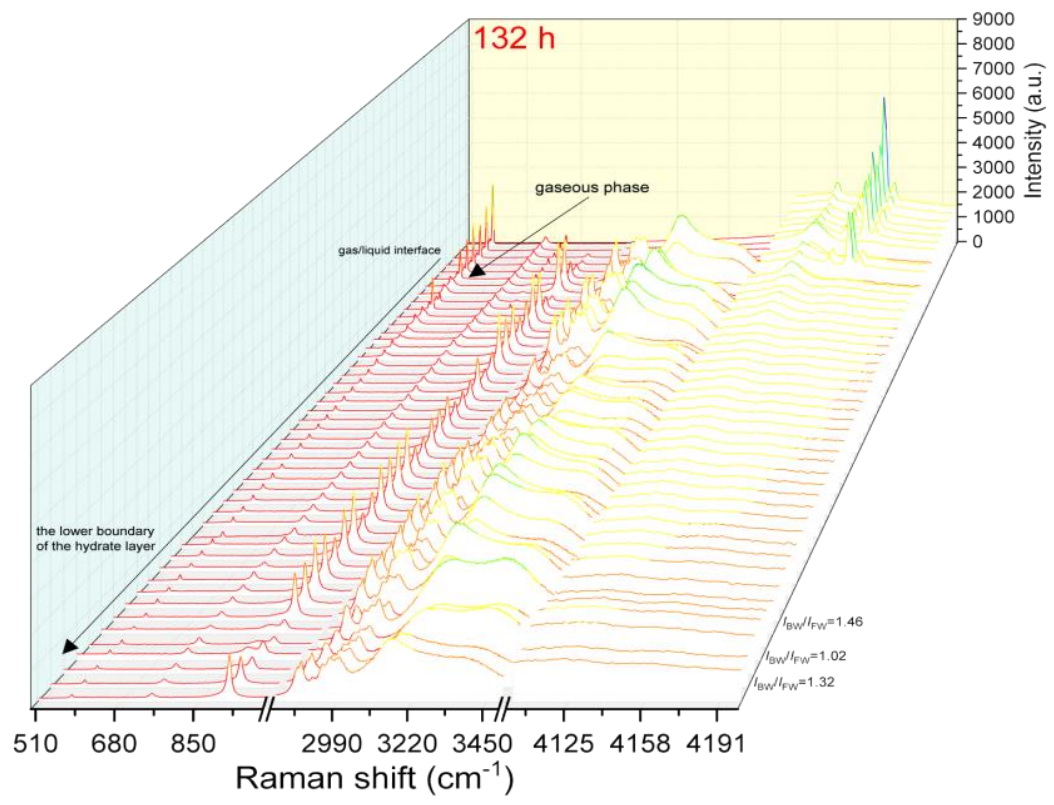

Fig. 10 Raman spectra for compounds from gas/liquid interface towards hydrate layer at $132 \mathrm{~h}$. 